\title{
Quality of Life
}

National Cancer Institute

\section{Source}

National Cancer Institute. Quality of Life. NCI Thesaurus. Code C17047.

The subjective measurement of an individual's sense of well-being and ability to enjoy life. The concept holds varying meanings for different people and may evolve over time. For some individuals it implies autonomy, empowerment, capability, and choice; for others, security, social integ ration, or freedom from stress or illness. 